\title{
FUNCTIONAL FINISHING OF CELLULOSIC MATERIAL BY MEANS OF ALKOXYSILANE/POLYMER COMPOSITES
}

\author{
CHRISTIAN SCHRAMM and ANGELIKA AMANN \\ Research Institute of Textile Chemistry and Textile Physics, University of Innsbruck, \\ Höchsterstrasse 73, A-6850 Dornbirn, Austria \\ × Corresponding author: Christian Schramm, christian.schramm@uibk.ac.at
}

Received October 30, 2018

Cotton fabrics were treated with solutions containing alkoxysilanes (tetraethoxysilane TEOS), (3glycidylpropyl)trimethoxysilane, GPTMS, (3-triethoxysilylpropyl)succinic acid anhydride, TESP-SA) in combination with organic polymers (poly(vinylalcohol), PVA), poly(ethylene oxide), PEO) and poly(vinylpyrrolidon), PVP). The impregnated cotton samples were thermally treated and the physical-mechanical properties were evaluated. The values of the dry crease recovery angle made evident that an improvement of the crease resistance could be obtained, whereas the tensile strength was reduced. The water retention value and the water vapor permeability were measured. The samples were studied by means of FT-IR, TGA and confocal laser microscopy.

Keywords: cotton, surface modification, sol-gel technique, organic polymers

\section{INTRODUCTION}

Cotton consists mainly of cellulose $(>97 \%)$, which is a fibre-forming, high molar mass polymer composed of a chain of repeating cellobiose units. The reactive sites of cellulose are primary and secondary alcohol groups, which enable the formation of intermolecular and intramolecular hydrogen bonding. ${ }^{1,2}$ Cellulosic materials possess various beneficial attributes, such as being developed from the most abundant raw organic material, the capability to absorb water, high thermal stability. However, cottonbased textiles have also undesired characteristics, such as low wrinkle resistance and shrinkage.

Therefore, a considerable amount of studies have been carried out to modify the surface of cellulose-based fabrics in an attempt to minimize the drawbacks or to impart novel functionalities to the cellulosic material. ${ }^{3-6}$ For this purpose, various approaches have been developed. Among these, the sol-gel method is a most important technique that has attracted extensive attention with regard to the modification of textile materials. ${ }^{7-10}$ Sol-gel processing is a chemical technology based on hydrolysis and subsequent condensation of metal or semimetal alkoxides (organo-silicates, titanates, -aluminates etc.). ${ }^{11,12}$ Textile systems are impregnated with a solution of hydrolyzed alkoxides and subsequently are subjected to thermal treatment for a specified cure time. Polymers have been also applied to convey novel properties to cotton fabrics. Thus, PVA was used to improve the easy-care characteristics of cellulosic textiles. $^{13}$

Cotton-based materials were coated with PVP to improve their performance properties. ${ }^{14-18}$ The treatment of textile materials with PEO also resulted in an alteration of their surface properties. ${ }^{19-21}$

The present study has been undertaken with a view to investigate the physical-mechanical properties of cotton samples that have been treated with finishing baths containing mixtures of tetraethoxysilane (TEOS), (3glycidyloxypropyl)trimethoxysilane (GPTMS), or (3-triethoxysilylpropyl)succinic acid anhydride (TESP-SA), in conjunction with an organic polymer, such as poly(vinylalcohol) (PVA), poly(vinylpyrrolidone) (PVP) or poly(ethylene oxide) (PEO).

\section{EXPERIMENTAL \\ Materials}

Tetraethoxysilane (98\%, TEOS) was supplied by Fluka Chemie GmbH, Buchs, Switzerland. (3Triethoxysilylpropyl)succinic acid anhydride (TESP- 


\section{CHRISTIAN SCHRAMM and ANGELIKA AMANN}

SA, 100\%) and (3-glycidyloxypropyl)trimethoxysilane (100\%, GPTMS) were obtained from Wacker Silicone, Burghausen, Germany. Poly(vinylalcohol), (98-99\% hydrolyzed, Mw 85.000-124.000, PVA), poly(ethylene oxide) (Mw 600.000, PEO) and poly(vinylpyrrolidone) (Mw 1.300.000, PVP) were purchased from SigmaAldrich, St. Louis, USA. The chemical formula of the substances can be seen in Figure 1. The chemicals were applied without further purification. Deionized water (DI) was used throughout the investigation. Desized, scoured, bleached and mercerized $100 \%$ cotton fabric (weave type: plain, density warp: 52 yarn $/ \mathrm{cm}$, weft: 24 yarn $/ \mathrm{cm}$, weight: $109 \mathrm{~g} / \mathrm{m}^{2}$ ) was utilized throughout the study.

\section{Preparation of alkoxysilane and polymer solutions}

The finishing solutions were prepared as follows: $15 \mathrm{mmol}$ and $30 \mathrm{mmol}$, respectively, of each of the alkoxysilanes (TEOS, GPTMS, TESP-SA) were hydrolyzed in $30 \mathrm{~mL} \mathrm{DI}$ and $5 \mathrm{~mL} \mathrm{HCl}(\mathrm{c}=0.1 \mathrm{~mol} / \mathrm{L})$ at room temperature for $3 \mathrm{~h}$, under stirring in a $\mathrm{PE}$ beaker, which was sealed with a pierced parafilm. Then, $50 \mathrm{~mL}$ of a PVA solution $10 \%(\mathrm{w} / \mathrm{w})$ or PVP solution $10 \%(\mathrm{w} / \mathrm{w})$, or PEO solution $5 \%(\mathrm{w} / \mathrm{w})$, respectively, was added under stirring for $10 \mathrm{~min}$ at RT. Subsequently, the volumes of the homogenous solutions were filled up to $100 \mathrm{~mL}$ with DI.

\section{Preparation of cotton samples}

The pre-weighed cotton samples were impregnated with the corresponding alkoxide solutions, applying a two-roll laboratory padder (HVL 500 Mathis AG, Niederhasli, Switzerland; air pressure of 1 bar, rotary speed of $3 \mathrm{~m} / \mathrm{min}$ ). The samples were dried at $105{ }^{\circ} \mathrm{C}$ for $2 \mathrm{~min}$ in a lab dryer (LTE, W. Mathis AG, Switzerland). The condensation reaction was conducted at $140{ }^{\circ} \mathrm{C}$ for $20 \mathrm{~min}$. The scheme of preparation is shown in Figure 2.

\section{Apparatus and methods}

The add-on of the fabric weight was calculated as follows: add-on $(\%)=\left[\left(\mathrm{W}_{2}-\mathrm{W}_{1}\right) / \mathrm{W}_{1}\right] \times 100$; where $\mathrm{W}_{1}$ and $\mathrm{W}_{2}$ are the weights of the fabric specimens before and after treatment, respectively. Dry crease recovery angle (DCRA) was measured according to ISO 2312: 10 test specimens were creased and compressed under controlled conditions of time and load. After removal of the creasing load, the angle formed between the two limbs was measured. The DCRA values render possible the evaluation of a cross-linking reaction between a crease-resistant finishing agent and the cellulosic material. Tensile strength (TS) was determined with a Material Testing System Z010 (Zwick/Roell, Ulm, Germany), according to DIN EN ISO13934. The stiffness of the fabrics was determined by means of a Taber Stiffness Tester, Model 112, New York, USA, according to ASTM D 1388-R6. Flexural rigidity was calculated as described in ASTM D 1388-R6. Abrasion tests were performed according to DIN EN ISO 12947 (Martindale method): a circular sample was mounted on a specimen holder and subjected to a defined load (12 kpa). Then, it was rubbed against a standard fabric in a translational movement. The measurement of the air permeability was conducted according to DIN EN ISO 9237 using a Textest FX 3030 LDM air permeability tester, Textest Ldt., Zurich, Switzerland. The air flux (L/dm $/ \mathrm{min}$ ) passing through the fabric was evaluated at a pressure difference of $100 \mathrm{~Pa}$. Colorimetric data measurements were conducted with a CM-3610d Spectrophotometer from Konica Minolta, Japan. The CM-S100w Spectra Magic NX V1.9 color data software was used for data acquisition.<smiles>CCO[Si](OCC)(OCC)OCC</smiles>
Tetraethoxysilane
TEOS

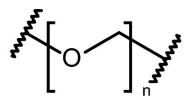

Poly(ethylenoxide) PEO<smiles>CO[Si](CCCCOC1CO1)(OC)OC</smiles>

(3-Glycidyloxypropyl)trimethoxysilane GPTMS

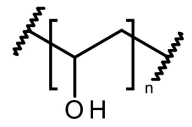

Poly(vinylalcohol) PVA<smiles>CCO[Si](CCCCCCCC(=O)OC(=O)CC)(OCC)OCC</smiles>

(3-Triethoxysilylpropyl)succinic acid TESP-SA

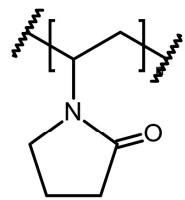

Poly(vinylpyrrolidone) PVP

Figure 1: Chemical formula of the compounds used in the study 


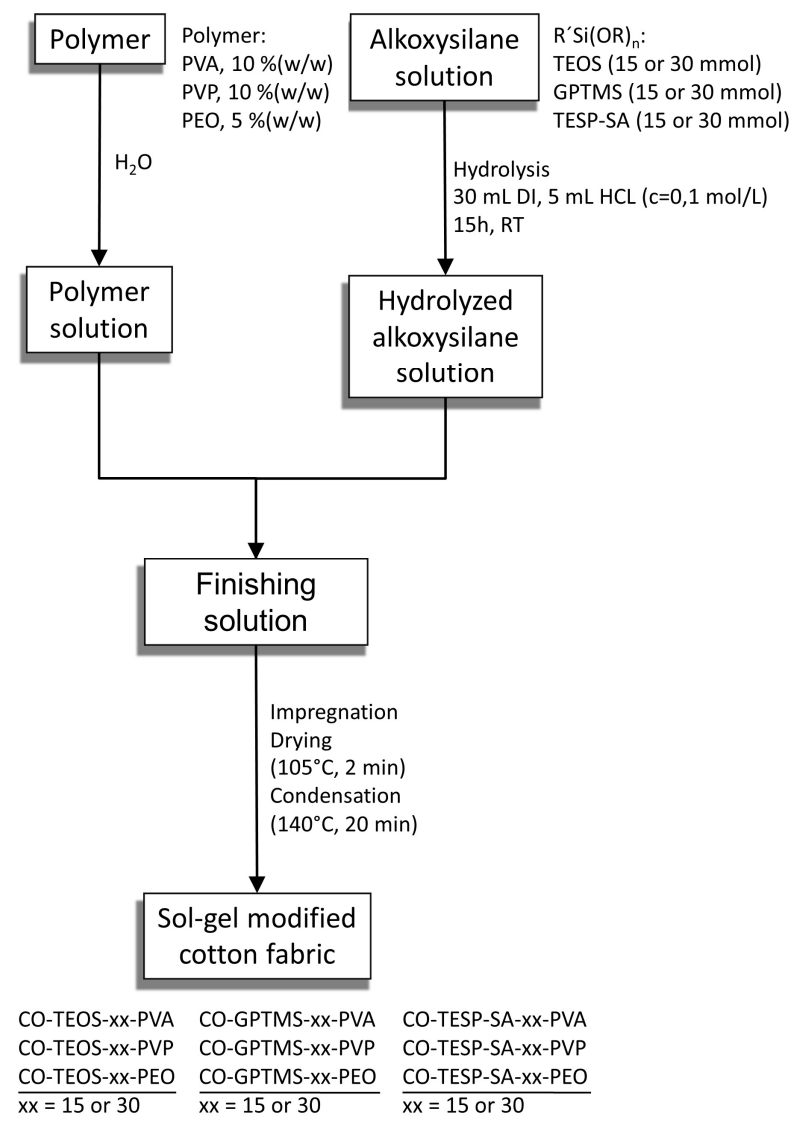

Figure 2: Scheme of finishing procedures for the preparation of organosiliconalkoxide/polymer modified cotton samples

The water retention value was measured on dried samples, which were allowed to swell in DI at room temperature for 2 hours. Subsequently, the samples were centrifuged for $20 \mathrm{~min}$ at $3000 \mathrm{rpm}$. After the centrifugation process, the samples were weighed $\left(\mathrm{W}_{2}\right)$ and dried for $4 \mathrm{~h}$ at $105{ }^{\circ} \mathrm{C}$ and reweighed $\left(\mathrm{W}_{1}\right)$. The water retention value (WRV) was calculated according to the following equation: $\mathrm{WRV}(\%)=\left[\left(\mathrm{W}_{2}-\mathrm{W}_{1}\right) / \mathrm{W}_{1}\right]$ $\mathrm{x} 100$. The water vapor permeability (WVP) was studied gravimetrically by placing disks covered with cellulosic specimens in a desiccator at $100 \%$ air humidity, at $23{ }^{\circ} \mathrm{C}$ for $96 \mathrm{~h}$. The WVP rate was measured gravimetrically using the water method, following ASTM E96. A plastic cup (4 cm diameter, $2.5 \mathrm{~cm}$ height, $25 \mathrm{~mL}$ ) was partially filled with DI (11 $\mathrm{mL})$. A hole ( $1.5 \mathrm{~cm}$ diameter) in the lid of the cup was sealed with the circular test specimen. This cup assembly was placed in a desiccator filled with silica gel. The initial weight of the assembly was taken and it was reweighed after $96 \mathrm{~h}$.

FT-IR/ATR spectra were recorded with a Bruker Vector 22 spectrometer, using a DTGS detector. The spectra were the result of 50 scans. The spectral resolution was $4 \mathrm{~cm}^{-1}$. A PIKE MIRacle TM ATR accessory equipped with a diamond ATR crystal was used. The surface morphology was studied by means of a 3D laser confocal microscope (Keyence VKX150, Osaka, Japan). TG measurements were conducted with a Linseis STA PT1000 thermogravimetric analyzer (heating rate of $10^{\circ} \mathrm{C} / \mathrm{min}$; scan range of $40-900^{\circ} \mathrm{C}$ ) in air.

\section{RESULTS AND DISCUSSION}

The surface of cellulosic materials can be chemically and physically modified in an attempt to impart various properties to the textile fabric. For this purpose, different chemical agents are applied to the material. By thermal treatment, a chemical reaction of the additive with the hydroxyl groups of the cellulose occurs, thus resulting in permanent fixation of the additive on the cotton fabric. Tetraalkoxysilane and organotrialkoxysilanes, such as TEOS, GPTMS and TESP-SA, contain a central silicon atom, to which reactive alkoxy groups and/or organic groups are attached. These reactive groups are 
subjected to an acidic or alkaline catalyzed hydrolysis reaction, resulting in the formation of a nanosol solution containing silanol groups. By an aging process or thermal treatment, these silanol groups are converted into siloxane groups, thus forming a gel. The nanosol solution or the gel solution can be applied to textile materials.

\section{Physical-mechanical properties of fabrics}

Cotton fabrics have been treated with various finishing baths containing the hydrolyzed alkoxides TEOS, GPTMS or TESP-SA (15 $\mathrm{mol} / 100 \mathrm{~mL}$ and $30 \mathrm{mmol} / 100 \mathrm{~mL}$ ), in combination with a polymeric material: PVA, PVP, PEO. The as-prepared cotton samples were thermally treated and the physical-mechanical properties were measured. The results are presented in Table 1.

\section{Uptake/add-on}

The add-on provides information on the portion of the chemical agent that was attached to the textile material. The cotton sample that was impregnated with the solution containing solely PVA (CO-PVA) showed the highest add-on value, compared to those with CO-PVP and COPEO, although PVA has the lowest Mw. This phenomenon can be explained by the fact that the hydroxyl groups of PVA form H-bonds with the functional groups of cellulose. The add-on values of the GPTMS and TESP-SA based cotton fabrics (CO-GPTMS-15, CO-GPTMS-30; CO-TESP-SA15, CO-TESP-SA-30) are higher in comparison with those of the samples treated with TEOS (CO-TEOS-15, CO-TEOS-30). This observation may be due to the fact that the hydrolysis of the epoxide group in GPTMS results in the formation of additional hydroxyl groups, whereas the anhydride functionality of TESP-SA is converted into carboxyl groups. Both reactions increase the amount of reacting sites for the interaction with the polymeric material. When TEOS, GPTMS or TESP-SA was applied, in combination with the polymers PVA, PVP or PEO, an additional increase in the add-on values can be observed. The highest values were obtained for the samples that were impregnated with PVA containing finishing solutions (CO-TE-30-PVA, COGPTMS-30-PVA, CO-TEP-SA-30-PVA).

\section{Dry crease recovery angle analysis}

Cotton fabrics tend to wrinkle. As a consequence, ironing is necessary in an attempt to remove the creases. DCRA is an excellent parameter to indicate the capability of cotton fabrics to recover. The results of the DCRA measurements are given in Table 1. An inspection of the values makes evident an increase in the crease resistance. The best values can be found for the cotton samples that were impregnated with GPTMS and TESP-SA based formulations. However, it is necessary to point out that the crease resistance performance of the DMDHEU treated cotton fabrics could not be achieved.

\section{Tensile strength}

Chemical modification of cotton fabrics influences their tensile strength. Thus, the crosslinking of the cellulose chains results in an increase in the crease resistance, but also results in a reduction of the tensile strength, since the intermolecular crosslinking restricts the relative movement of the cellulose chains, and therefore the distribution of stress cannot be equalized on the individual chains. The results shown in Table 1 reveal that the chemical modification of all the cotton samples gives rise to a decrease in the tensile strength values. The highest reduction can be observed for the samples that were treated with the polymer PEO (CO-TE-30-PEO, CO-GPTMS30-PEO, CO-TESP-SA-30-PEO).

\section{Flexural rigidity}

Various investigations make evident that the chemical modification of cellulosic fabrics leads to an increase in stiffness indicated by flexural rigidity (FR). The results presented in Table 1 make evident that cotton fabrics that were treated with mixtures containing a hydrolyzed alkoxysilane (TEOS, GPTMS, TESP-SA) and PVA or PVP presented a significant enhancement of the FR values. This phenomenon cannot be observed for the cotton fabrics cured with alkoxysilane/PEO-containing finishing baths. This effect can be explained by the fact that PVA and PVP contain functional groups that are susceptible to strong $\mathrm{H}$-bonding interactions. The findings are consistent with the results of the addon measurements.

\section{Whiteness index}

When cellulosic material is subjected to thermal treatment, a yellowing effect can be observed, which is due to the formation of unsaturated conjugated groups built by thermal oxidation. The results of the WI evaluation are shown in Table 1, indicating that the values of the WI are reduced in the range from 5 to $15 \%$, 
compared to the untreated fabric. The lowest values were measured for the cotton samples that were treated with PVA-containing finishing baths, whereas the PEO-based cotton samples have the highest values.

\section{Abrasion}

Since high abrasion resistance for textile materials is a very desirable property for almost all types of textile fabrics, the abrasion properties of the prepared cotton specimens have been tested. Figure 3a shows the abrasion curves of the cotton samples treated solely with the polymer. The findings evidence that the weight losses of the PVA and PVP treated specimens are low, whereas the abrasion curves of the untreated cotton fabric and PEO treated fabric are almost identical. Figure $3 b$ reflects the abrasion properties of the TEOS/polymer treated fabrics. In these cases, the same tendency can be detected. A high weight loss can be observed for the TEOS/PEO treated cotton fabrics, whereas the treatment of cotton fabrics with the combined TEOS/PVA and TEOS/PVP containing finishing solutions results in improved abrasion properties. Figure $3 \mathrm{c}$ shows the abrasion curves of the GPTMS/polymer composites treated cotton. The best abrasion resistance can be observed for COGPTMS-30. The GPTMS/PEO and GPTMS/PVA treated cotton specimens exhibit the highest weight losses, whereas the abrasion performance of the samples modified with PVP is significantly increased. Figure $3 \mathrm{~d}$ provides information on the abrasion behavior of the TESP-SA/polymer composites.

Table 1

Physical-mechanical properties (add-on, DCRA, TS, tensile strength, flexural rigidity, whiteness index) of the modified cotton samples

\begin{tabular}{|c|c|c|c|c|c|}
\hline Sample code & $\begin{array}{l}\text { Add-on } \\
(\%)\end{array}$ & $\begin{array}{c}\text { DCRA } \\
(\%)\end{array}$ & $\begin{array}{c}\text { Tensile strength } \\
(\%)\end{array}$ & $\begin{array}{c}\text { Flexural rigidity } \\
(\%)\end{array}$ & $\begin{array}{l}\text { WI } \\
(\%)\end{array}$ \\
\hline RM & & 100.0 & 100.0 & 100.0 & 100.0 \\
\hline CO-PVA & 2.30 & 114.2 & 61.1 & 751.4 & 90.6 \\
\hline CO-PVP & 1.92 & 111.5 & 49.1 & 926.5 & 91.6 \\
\hline CO-PEO & 0.54 & 132.1 & 44.4 & 100.6 & 94.7 \\
\hline CO-TE-15 & 0.60 & 131.8 & 57.2 & 40.6 & 94.0 \\
\hline CO-TE-30 & 1.01 & 132.1 & 79.2 & 74.2 & 91.4 \\
\hline CO-TE-15-PVA & 3.61 & 136.1 & 82.8 & 360.6 & 89.7 \\
\hline CO-TE-30-PVA & 4.85 & 139.9 & 83.4 & 1115.0 & 90.1 \\
\hline CO-TE-15-PVP & 2.52 & 128.7 & 73.6 & 476.9 & 92.3 \\
\hline CO-TE-30-PVP & 3.45 & 123.0 & 76.7 & 45.3 & 91.8 \\
\hline CO-TE-15-PEO & 1.52 & 135.5 & 52.0 & 47.0 & 96.0 \\
\hline CO-TE-30-PEO & 2.37 & 142.9 & 46.6 & 114.8 & 99.5 \\
\hline CO-GPTMS-15 & 1.18 & 146.3 & 69.5 & 82.3 & 95.6 \\
\hline CO-GPTMS-30 & 2.96 & 149.0 & 64.7 & 88.9 & 94.7 \\
\hline CO-GPTMS-15-PVA & 3.54 & 148.3 & 53.6 & 374.4 & 86.5 \\
\hline CO-GPTMS-30-PVA & 5.85 & 145.6 & 48.1 & 557.3 & 85.8 \\
\hline CO-GPTMS-15-PVP & 3.70 & 139.2 & 57.3 & 911.0 & 89.3 \\
\hline CO-GPTMS-30-PVP & 5.32 & 147.6 & 75.6 & 701.0 & 89.6 \\
\hline CO-GPTMS-15-PEO & 2.55 & 147.0 & 63.7 & 69.0 & 95.8 \\
\hline CO-GPTMS-30-PEO & 4.98 & 149.0 & 41.9 & 48.4 & 94.7 \\
\hline CO-TESP-SA-15 & 1.65 & 148.3 & 63.5 & 45.0 & 96.4 \\
\hline CO-TESP-SA-30 & 3.65 & 148.6 & 62.9 & 45.8 & 97.0 \\
\hline CO-TESP-SA-15-PVA & 4.12 & 138.5 & 51.2 & 487.0 & 92.7 \\
\hline CO-TESP-SA-30-PVA & 6.40 & 139.9 & 62.2 & 1093.4 & 91.3 \\
\hline CO-TESP-SA-15-PVP & 4.03 & 126.7 & 54.7 & 409.1 & 94.3 \\
\hline CO-TESP-SA-30-PVP & 5.95 & 117.9 & 44.7 & 1088.2 & 92.4 \\
\hline CO-TESP-SA-15-PEO & 2.86 & 148.3 & 35.2 & 102.2 & 97.5 \\
\hline CO-TESP-SA-30-PEO & 4.64 & 145.3 & 49.3 & 82.2 & 95.4 \\
\hline
\end{tabular}




\section{CHRISTIAN SCHRAMM and ANGELIKA AMANN}
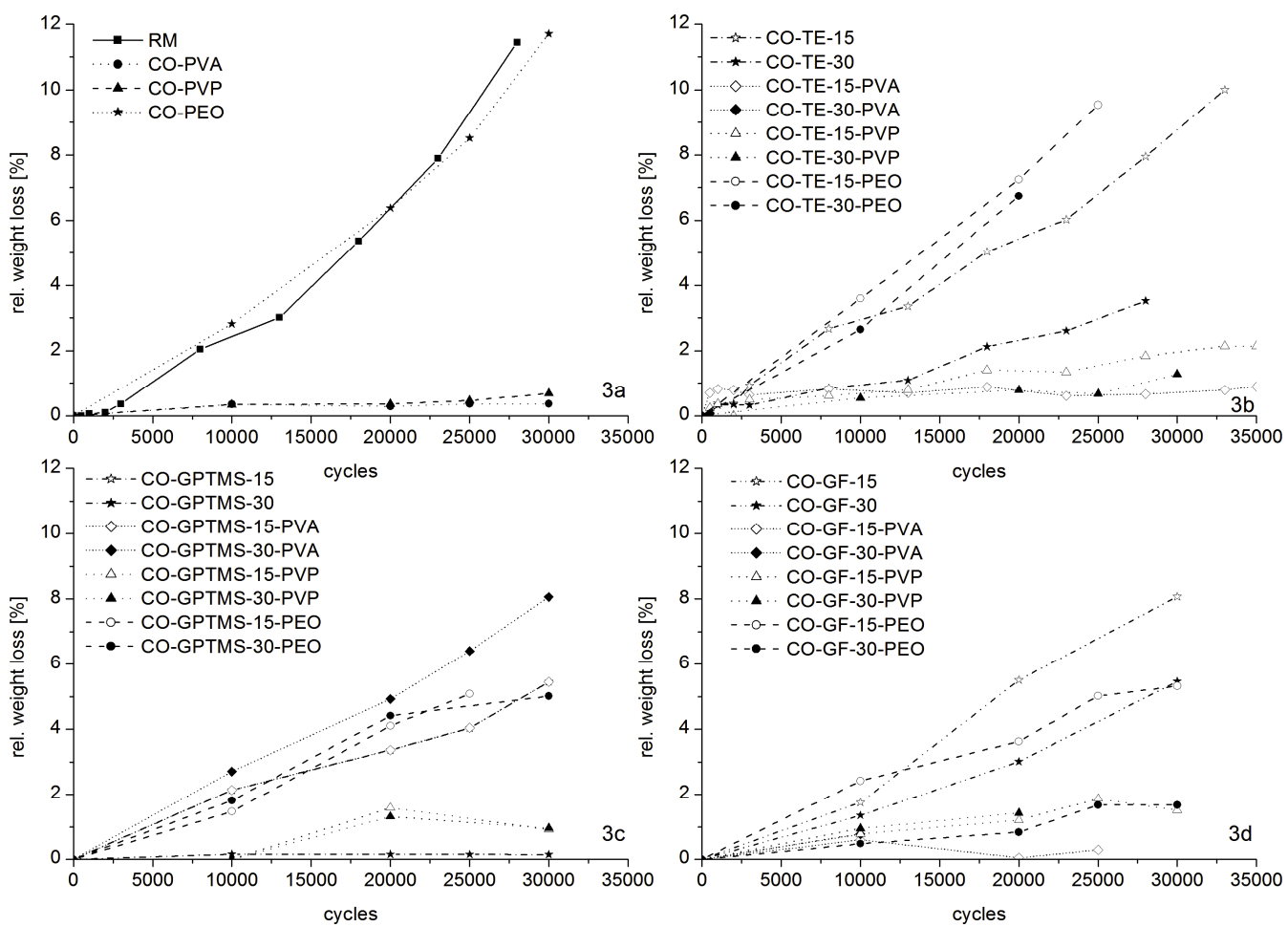

Figure 3: Abrasion curves of the raw material and polymer treated cotton samples (a), TEOS/polymer treated cotton samples (b), GPTMS/polymer treated cotton samples (c), and TESP-SA/polymer treated cotton samples (d)

The findings indicate that the best results were obtained for CO-TESP-SA-30-PVA. This result may be due to the fact that the hydroxyl groups of PVA react with the carboxyl groups of TESP-SA, thus forming a covalent ester-linkage.

\section{Water retention value and water vapor permeability}

The six hydroxyl groups of the cellobiose unit provide structural stability, as well as extensive intermolecular hydrogen bonding with many molecules, including water. Therefore, it is of high interest to investigate the interaction of the modified cotton samples with water. For this purpose, the water retention value and the water vapor permeability were measured.

Figure 4 provides the WRV of the treated cellulosic fabrics. One can note that the finishing of the cotton fabric results in an increase in the WRV. The largest increase can be observed for CO-TE-15-PVP, CO-TE-30, CO-PVP and COPVA.

Water vapor permeability (WVP) is also an important physical property of cellulose-based fabrics, affecting the wear comfort. The data of the WVP measurements are shown in Figure 4.
The results reveal that, in comparison with RM, no significant differences can be detected, except for the lower values of CO-TE-15-PVP, CO-TE30-PVP, CO-PEO and CO-TE-30-PVA.

\section{Surface morphology}

To study the morphological structure of the treated cotton samples, confocal microscopy was used. Figure 5 shows the images of the native cotton samples (Fig. 5a), of CO-TE-30-PVA (Fig. 5b), CO-GPTMS-30-PVA (Fig. 5c), and COTESP-SA-30-PVA (Fig. 5d), indicating that the treatment of the cellulosic samples does not result in a significant change of the surface structure.

\section{FT-IR analysis}

FT-IR/ATR measurements were carried out to gain a deeper insight into the chemical environment of the surface of the sol-gel modified cotton material. The spectra of RM, CO-PVA, CO-PVP and CO-PEO are shown in Figure 6a. One can notice that no significant difference of the spectra can be observed. Most of the absorption bands derive from the vibration modes of the cellulose and can be assigned as described below. 
The vibration mode at $896 \mathrm{~cm}^{-1}$ can be assigned to the asymmetric out-of-plane ring stretch of the $\beta$-glycosidic bond, whereas the band appearing at $1028 \mathrm{~cm}^{-1}$ is due to the $\mathrm{C}-\mathrm{O}$ stretching vibration. The peak observed at 1155 $\mathrm{cm}^{-1}$ is associated with the asymmetric C-O-C band. The band at $1319 \mathrm{~cm}^{-1}$ can be ascribed to the $\mathrm{CH}$ wagging bands. $1367 \mathrm{~cm}^{-1}$ is due to the
$\mathrm{OH}$ in-plane bending and the $1435 \mathrm{~cm}^{-1}$ band can be assigned to $\mathrm{CH}$ wagging (in-plane). The band at $1640 \mathrm{~cm}^{-1}$ stems from the $\mathrm{OH}$ stretching vibration of adsorbed water. The peak located at $1658 \mathrm{~cm}^{-1}$ can be observed only in the spectra of CO-PVP and is due to the carbonyl stretching of the cyclic amide group. The band at $2892 \mathrm{~cm}^{-1}$ is due to the $-\mathrm{CH}_{2}-$ stretching vibrations.

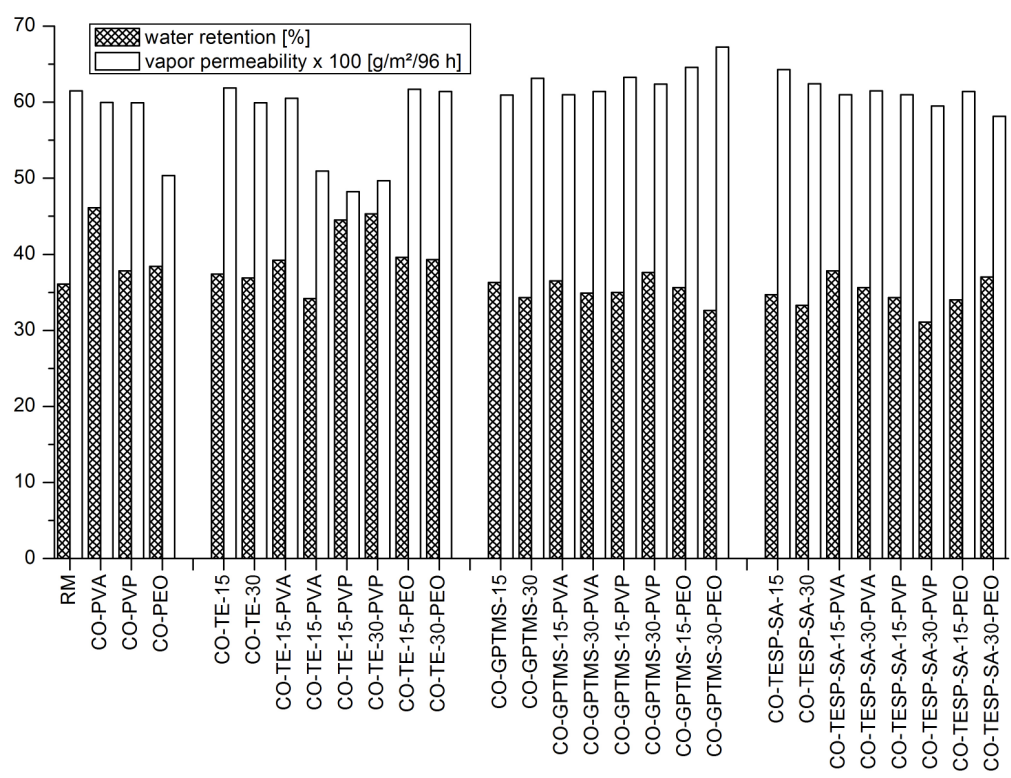

Figure 4: Water retention properties and vapor permeability of modified cotton samples
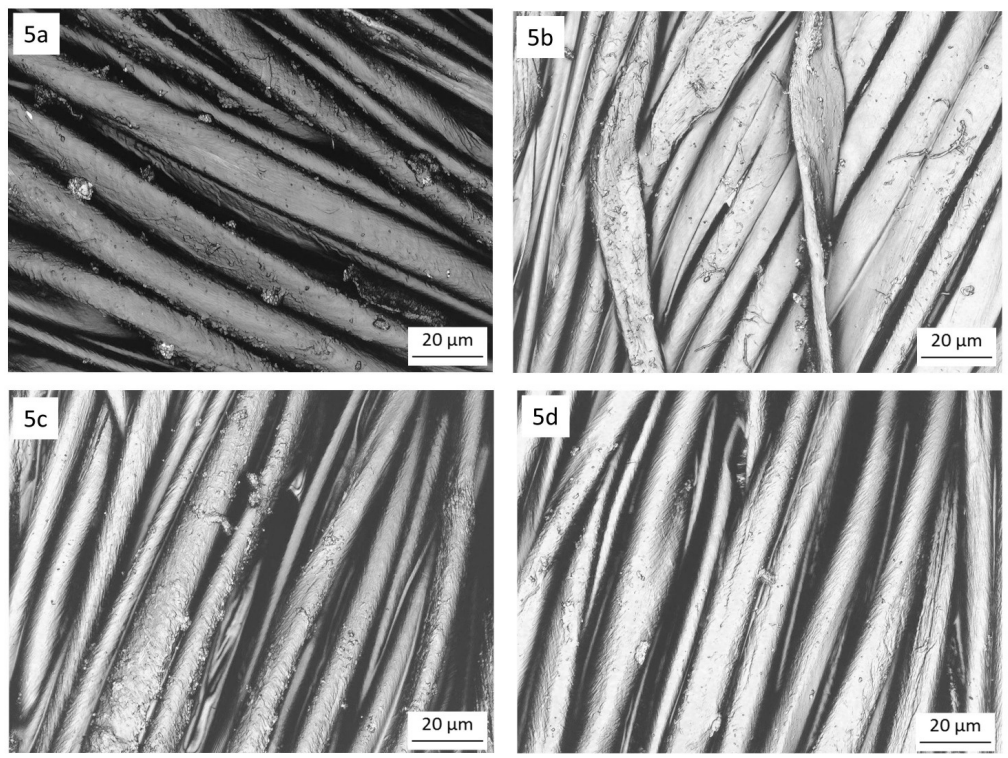

Figure 5: Confocal microscopy images of the raw material (a), CO-TE-30-PVA (b); CO-GPTMS-30-PVA (c), and COTESP-SA-30-PVA (d)

The vibrations appearing in the region from $3100 \mathrm{~cm}^{-1}$ to $3600 \mathrm{~cm}^{-1}$ are assigned to H-bonded
$\mathrm{OH}$ stretching vibrations. The $\mathrm{OH}$ absorption bands that can be observed at wavelengths higher 


\section{CHRISTIAN SCHRAMM and ANGELIKA AMANN}

than $3400 \mathrm{~cm}^{-1}$ are assigned to intramolecular hydrogen bonds. Those at wavenumbers lower than $3400 \mathrm{~cm}^{-1}$ are due to intermolecular hydrogen bonds. ${ }^{22-24}$

Consequently, the shoulder at $3440 \mathrm{~cm}^{-1}$ can be ascribed to intramolecular hydrogen bonds, whereas the absorption bands at 3332 and 3283 $\mathrm{cm}^{-1}$ confirm the presence of intermolecular hydrogen bonds.

Figure $6 b$ shows the spectra of the TEOS/polymer treated cotton fabric, indicating that almost no differences between the spectra can be detected, except the fact that the spectrum of CO-TEOS-30-PVP exhibits a peak at $1658 \mathrm{~cm}^{-1}$, which is assigned to the carbonyl stretching of the cyclic amide bond. An almost identical phenomenon can be observed for the GPTMS/polymer spectra, which can be seen in
Figure 6c. A noteworthy aspect of these spectra is that no absorption band is visible at $1255 \mathrm{~cm}^{-1}$, indicating that no epoxide ring is present. The inspection of the spectra of the TESP-SA/polymer composite reveals that an additional peak appears at $1722 \mathrm{~cm}^{-1}$, indicating the presence of a carboxyl carbonyl group (Fig. 6d).

\section{Thermogravimetric analysis}

When cellulose-based materials, as well as polymers, are subjected to thermal treatment at elevated temperatures, then various processes, such as depolymerisation, chain scission, oxidation, dehydration and decarboxylation, may occur. Therefore, it is of high interest to investigate the thermal behavior of alkoxide/polymer composites.

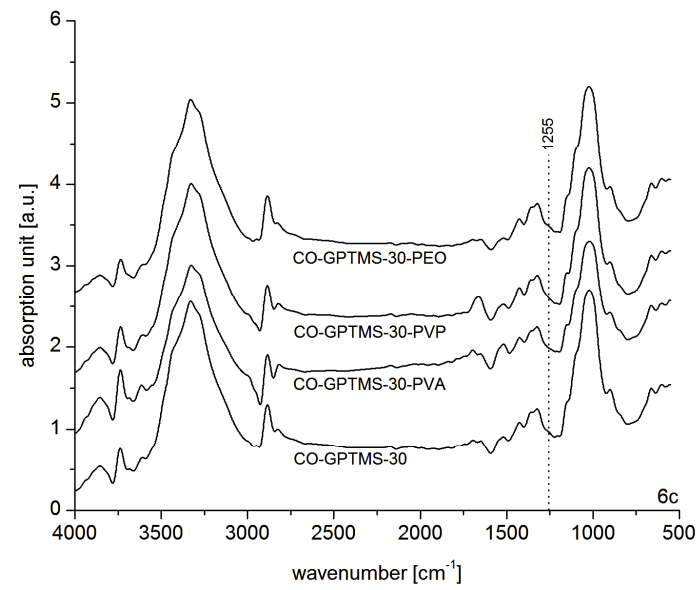

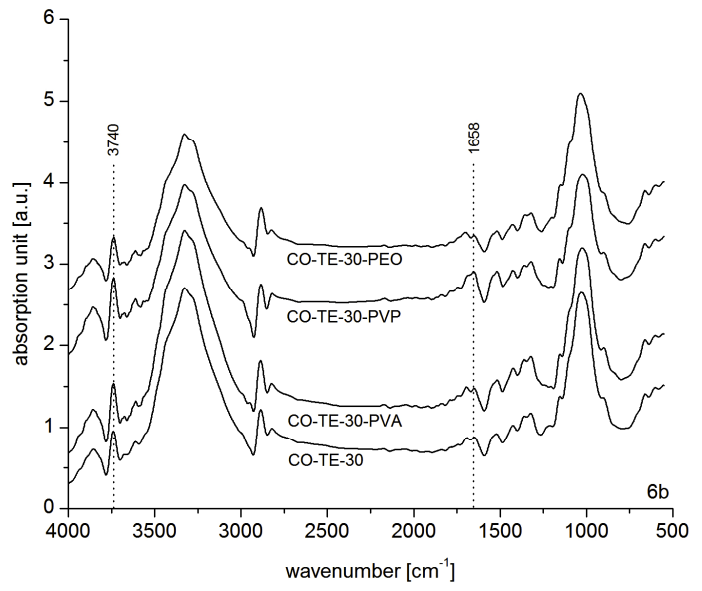
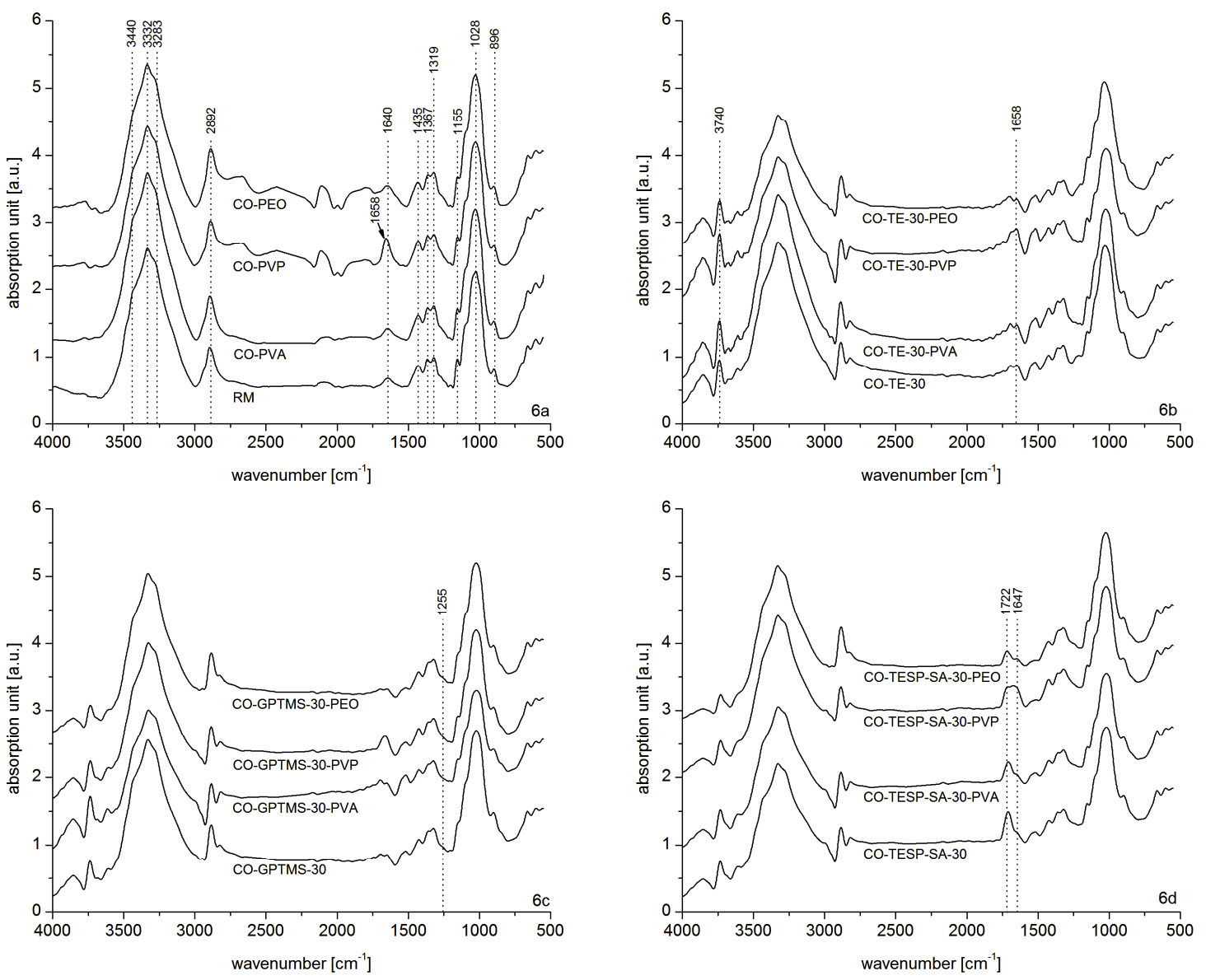

Figure 6: FT-IR spectra of the raw material and polymer treated cotton samples (a), TEOS/polymer treated cotton samples (b), GPTMS/polymer treated cotton samples (c), and TESP-SA/polymer treated cotton samples (d) 

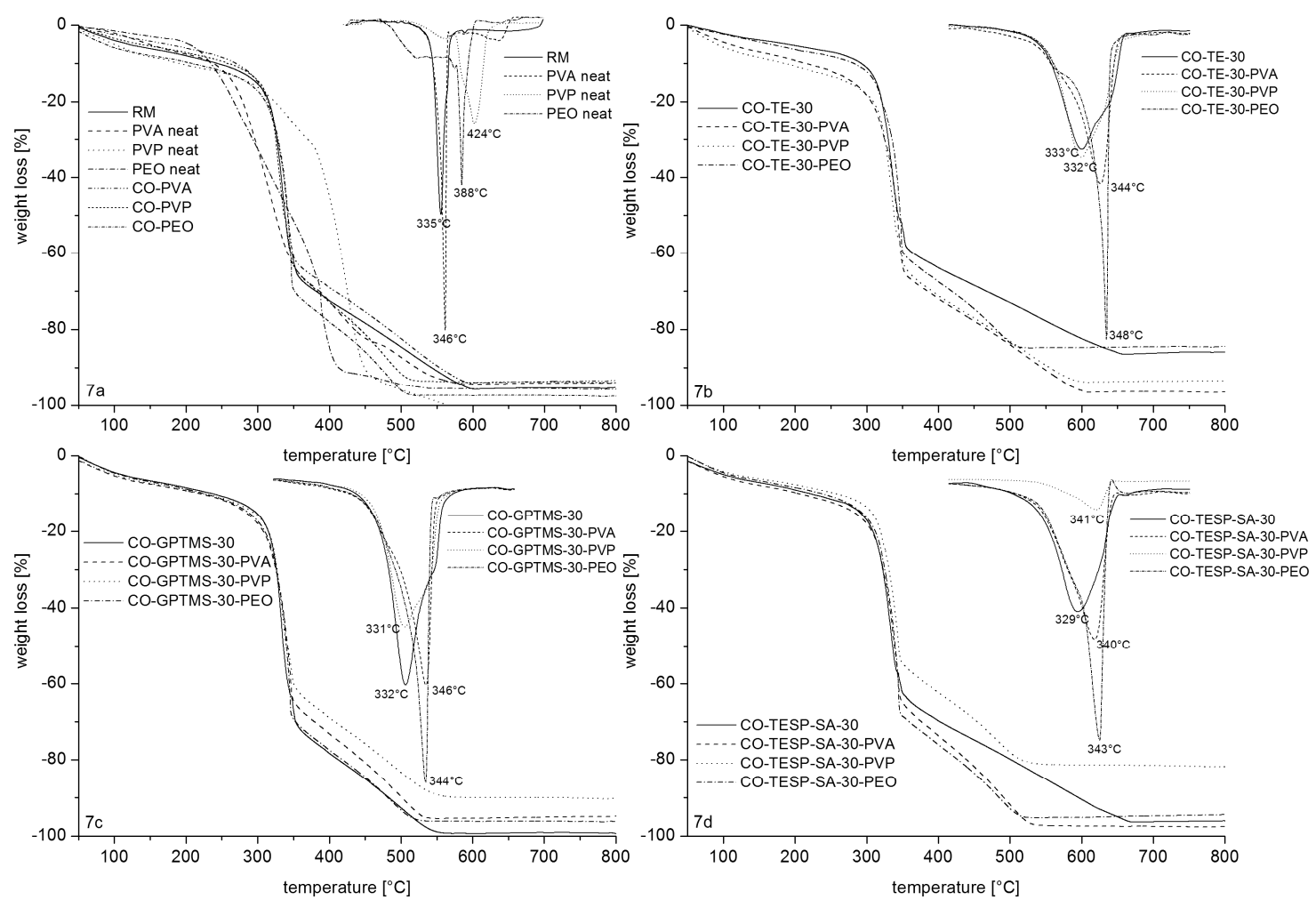

Figure 7: TGA curves of the raw material, pristine polymers and polymer treated cotton samples (a), TEOS/polymer treated cotton samples (b), GPTMS/polymer treated cotton samples (c), and TESP-SA/polymer treated cotton samples (d)

Figures $7 \mathrm{a}-7 \mathrm{~d}$ describe the thermal behavior of the cotton fabrics treated with various alkoxysilane/polymer composites. Figure $7 \mathrm{a}$ shows the TG and DTG curves of the raw material, the neat polymers and the cotton fabrics finished with the polymer. The DTG curves reveal that RM has the lowest peak temperature $\left(T_{m}\right)$, whereas neat PVP shows the highest $T_{m}$ value. The findings are consistent with those found in the literature. ${ }^{25-27}$ In Figure $7 \mathrm{~b}$, the TG and DTG profiles of the cotton samples treated with TEOS/polymer-containing solutions can be seen. The values of the peak temperatures are in the range from $333{ }^{\circ} \mathrm{C}$ to $348{ }^{\circ} \mathrm{C}$. Almost identical thermal characteristics can be observed for the specimens finished with GPTMS/polymer (Fig. 7c) or TESP-SA/polymer (Fig. 7d).

\section{CONCLUSION}

Cotton-based material was treated with solutions containing an alkoxysilane (TEOS, GPTMS, TESP-SA), in combination with an organic polymer (PVA, PVP, PEO). The measurement of the physical-mechanical properties revealed an improvement of the DCRA values and an increase in stiffness. Only slight effects were obtained for the PEO treated fabrics. From the WRV values and the WVP values, it can be concluded that the TEOS treated samples show the most significant effect.

ACKNONOWLEDGMENTS: The authors gratefully acknowledge the FFG (Österreichische Forschungsförderungsgesellschaft) for financial support of the project 846932 (Endowed Professorship in Advanced Manufacturing). The authors would like to thank the Testing Institute of the HTL Dornbirn (Austria) for the use of their facilities.

\section{REFERENCES}

A. O'Sullivan, Cellulose, 4, 173 (1997), DOI: 10.1023/A: 1018431705579

2 R. J. Moon, A. Martini, J. Nairn, J. Simonsen and J. Youngblood, Chem. Soc. Rev., 40, 3941 (2011), DOI: 10.1039/C0CS00108B 


\section{CHRISTIAN SCHRAMM and ANGELIKA AMANN}

3 S. B. Vukusic, D. Katovic and C. Schramm, Text. Res. J., 73, $733 \quad$ (2003), https://doi.org/10.1177/004051750307300812

4 Y. L. Lam, C. W. Kan, C. W. M. Yuen and C. H. Au, J. Appl. Polym. Sci., 119, 2875 (2011).

${ }^{5}$ A. Hebeish, M. Hashem, A. Abdel-Rahman and Z. H. El-Hilw, J. Appl. Polym. Sci., 100, 2697 (2006), https://doi.org/10.1002/app.22916

6 A. Nazari, M. Montazer, M. B. Moghadam and M. Anary-Abbasinejad, Carbohyd. Polym., 83, 1119 (2011), https://doi.org/10.1016/j.carbpol.2010.09.015

7 B. Mahltig and T. Textor, "Nanosols and Textiles", World Scientifics, London, 2008.

8 C. Schramm, B. Rinderer, W. Binder, R. Tessadri and H. Duelli, in "Recent Research Development in Applied Polymer Science", edited by S. G. Pandalai, Vol. 3., pp. 37-56.

9 B. Mahltig, H. Haufe and H. Boettcher, J. Mater. Chem., 15, 4385 (2005), DOI: 10.1039/B505177K

10 C. Schramm, B. Rinderer, W. Binder, R. Tessadri and H. Duelli, J. Sol-Gel Sci. Technol., 45, 83 (2008), DOI: $10.1007 / \mathrm{s} 10971-007-1627-6$

11 C. J. Brinker and G. W. Scherer, "Sol-Gel Science, The Physics and Chemistry of Sol-Gel Processing", Academic Press, San Diego, 1990.

12 L. L. Hench and J. K. West, Chem. Rev., 90, 33 (1990), https://doi.org/10.1021/cr00099a003

13 W. L. Zhou, C. Q. Yang and G. C. Lickfield, J. Appl. Polym. Sci., 91, 3940 (2004), https://doi.org/10.1002/app.13606

14 Q.-Z. Yu and A.-A. Shen, J. Fiber Bioeng. Informat., 1, 65 (2008), doi:10.3993/jfbi06200809

15 A. P. S. Immich, P. H. H. de Araújo, L. H. Catalani, A. A. U. de Souza and S. M. A. G. U. Souza,
Polym. Eng. Sci., 51, 445 (2011), https://doi.org/10.1002/pen.21845

16 S. Selvam and M. Sundrarajan, Carbohyd. Polym.,

87, 1419 (2012),

https://doi.org/10.1016/j.carbpol.2011.09.025

17 H. M. Fahmy, J. Ind. Text., 39, 109 (2009), https://doi.org/10.1177/1528083709102932

18 H. M. Fahmy and E. S. Abdel-Halim, J. Ind. Text., 40, 109

(2010), https://doi.org/10.1177/1528083709350185

19 S. Kiatkamjornwong, P. Putthimai and H. Noguchi, Surf. Coat. Int. B: Coat. Trans., 88, 25 (2005), https://doi.org/10.1007/BF02699704

20 A. Vilcnik, I. Jerman, A. Surca Vuk, M. Kozelj et al., Langmuir, $\quad \mathbf{2 5}, 5869 \quad$ (2009), https://doi.org/10.1021/la803742c

21 A. Asghar, Y. A. Samad and R. Hashaikeh, $J$. Appl. Polym. Sci., 125, 2121 (2012), https://doi.org/10.1002/app.36303

22 T. Kondo and C. Sawatari, Polymer, 31, 293 (1996), https://doi.org/10.1016/0032-3861(96)82908-9

23 T. Kondo, Cellulose, 4, 281 (1997), https://doi.org/10.1023/A:1018448109214

24 Y. Hishikawa, S.-I. Inoue, J. Magoshi and T. Kondo, Biomacromolecules, 6, 2468 (2005), https://doi.org/10.1021/bm050032k

25 D. Ciolacu and V. I. Popa, Cellulose Chem. Technol., 40, 445 (2006).

${ }^{26}$ F. M. Silva, A. C. da Silva, C. F. Fogo, G. E. A. Pineda and W. A. A. Hechenleitner, J. Therm. Anal. Calorim., $\quad 79, \quad 367 \quad$ (2005), https://doi.org/10.1007/s10973-005-0066-2

27 R. Mishra and K. J. Rao, Eur. Polym. J., 35, 1883 (1999), https://doi.org/10.1016/S0014-3057(98)002833 